\title{
Application of Extension Theory with Chaotic Signal Synchronization on Detecting Islanding Effect of Photovoltaic Power System
}

\author{
Meng-Hui Wang, ${ }^{1}$ Mei-Ling Huang, ${ }^{2}$ and Kang-Jian Liou ${ }^{1}$ \\ ${ }^{1}$ Department of Electrical Engineering, National Chin-Yi University of Technology, Sec. 2, 57 Chung Shan Road, \\ Taiping, Taichung, Taiwan \\ ${ }^{2}$ Department of Industrial Engineering \& Management, National Chin-Yi University of Technology, Sec. 2, \\ 57 Chung Shan Road, Taiping, Taichung, Taiwan
}

Correspondence should be addressed to Mei-Ling Huang; huangml@ncut.edu.tw

Received 15 December 2014; Revised 5 March 2015; Accepted 5 March 2015

Academic Editor: Leonardo Palmisano

Copyright (C) 2015 Meng-Hui Wang et al. This is an open access article distributed under the Creative Commons Attribution License, which permits unrestricted use, distribution, and reproduction in any medium, provided the original work is properly cited.

The detection of islanding effect is a highly important topic for photovoltaic (PV) power system. The islanding effect occurs when the distributed power source is disconnected from the main supply while the power is still supplied in partial load area, which may injure the set maintenance personnel or damage the equipment. Combining chaotic synchronization and extension theory, this research is to propose a novel detection method to distinguish the occurrence of islanding effect based on nonautonomous Chua's circuit. To demonstrate the effectiveness of the proposed method, this paper applies PSIM to simulate the PV power system. The experimental results show that the accuracy of the proposed method achieves $98 \%$ on islanding effect.

\section{Introduction}

In recent years, Taiwan's rapid industrial development has led to increasing demand on fossil energy. Topics of the environmental protection, sustainable resources application, and green energy industry have drawn more attention [1]. In terms of green energy, the photovoltaic (PV) and wind power development is relatively mature. Taiwan, as a small island, has limited natural resources to develop wind power. First, it is more difficult to install wind turbines on the sea, as compared to install PV power system on the land [2]. Second, the peak period of energy consumption is in the summer, while it is the lowest power generation season for wind power. The location of Taiwan is on latitude of 23.5 degrees north with abundant sunshine in the summer and is suitable for developing PV power system. The annual power generation is about 48,917 MWh in Taiwan [3]. Recently, Taiwan has been promoting PV power system, and the total installed capacity reached $296 \mathrm{MW}$ in 2014.

The output of PV system is DC, which must be converted into $\mathrm{AC}$ by inverter before it is connected parallel to the main supply. The phenomenon is called islanding effect when both the load and PV power system are disconnected from the load simultaneously, and the PV power system still supplies power to the load. Once the islanding effect occurs and the PV power system is not disconnected from the load instantly, it will result in the casualties of maintenance personnel or cause the heavy damage on power users, power supply system, or electrical equipment. With the construction of different distributed power source and power network parallel systems, once the mains supply is disconnected by fault, the hazard probability of islanding effect increases relatively. Therefore, the prevention and detection of islanding effect are crucial on the application of renewable energy. 
There are two main categories for islanding detection: active and passive methods. The active detection method is designed to directly and actively detect the part of the network and then distinguish the signal changes, while the passive detection method monitors system parameters to disconnect from the load when nonnormal condition occurs without directly interacting with the system. Compared to the passive method, active method is more effective. However, the effectiveness of active method may become the adversity to the system, and besides it requires higher implementation cost than passive method $[4,5]$. Many recent studies have proposed islanding operation prevention methods, such as phase jump detection method [6], voltage harmonic detection method [7], and power variation rate detection method [8]. Those methods are relatively easy to be implemented. However, when the output power of electric governor and the load power of PV systems approach balance, the voltage and frequency changes of PV power system are insignificant, and the passive detection method often fails. All the above methods face the problem of nondetection zone and cannot independently detect the islanding effect.

Combining chaotic synchronization and the extension theory, this research is to propose a novel detection method to distinguish the occurrence of islanding effect based on nonautonomous Chua's circuit [9]. With simple structure, the nonautonomous Chua's circuit is easy to be implemented. The chaotic synchronization detection method and the extension theory have high computing speed, and both are likely to be implemented by chips not only to enhance the performance of nonautonomous Chua's circuit detection, but also to increase the accuracy of islanding detection.

\section{Summary of Islanding Effect}

The islanding effect is a phenomenon when the PV power system and the power network are connected in operation [10]. The connection between PV power system and power network is shown in Figure 1. The islanding effect refers to independent power supply of partial network when the electricity is interrupted and the power network has faults or powers off, but the PV power system fails to detect it immediately and the protection relay has not been cut off the system [11]. IEEE 1547, IEC 61727, and NEC 690 are the regulations for the parallel connection between distributed power source of power system and main supply. As more and more distributed power sources are connected parallel to the main supply network, the potential islanding problem becomes severe increasingly. Due to disconnection from main supply network, the distributed power source loses the reference of power supply from power company. Under independent operation of distributed power source, the power company cannot monitor the power system and the damage of household appliances or sensitive machines occurs.

When the islanding effect occurs, the voltage and frequency of distributed power source may be abnormal and cannot be monitored. A reliable PV power system should detect the occurrence of islanding effect and function in time to avoid damaging the load or injuring the maintenance

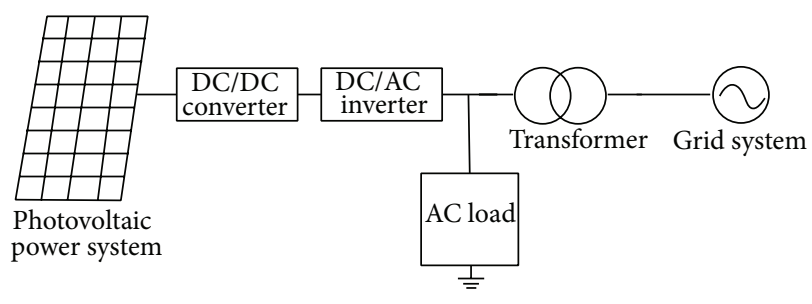

FIGURE 1: Photovoltaic power system links with grid system.

workers. The traditional islanding operation prevention methods are described below.

2.1. Phase Jump Detection Method. When the distributed power source is disconnected from main supply, the output requirement of distributed power source for load is unbalanced, so the inverter output current and load end voltage have phase difference with respect to different forms of load. The system determines whether the islanding effect is generated or not according to the phase difference. However, if the load is resistive, this method cannot recognize islanding effect successfully [6]. In addition, some loads, such as motors, cause temporary phase deviation at the moment of startup and will reduce the accuracy rate.

2.2. Voltage Harmonic Detection Method. The voltage harmonic detection method checks whether the voltage third harmonic distortion of load exceeds the threshold. If it does, the protection relay is cut off for islanding detection. The limitation of the method is due to nonlinear load and power quality in practice, and the threshold range of harmonic detection method is difficult to be determined; thus, the accuracy detection rate decreases [7].

\subsection{Power Changing Detection Method. Power changing} detection method identifies islanding effect based on the output power changing of inverter. When the main supply is disconnected from the distributed power source, the output power of inverter is significantly different from normal parallel connection, and the power variation rate is easily measured by power detection instrument. When the output power of PV power system approaches the load consumed power, the power of load is still in equilibrium state. When the PV power system cuts off the main supply, the output voltage still keeps the magnitude and frequency variation of normal main supply and it will result in misoperation of this detection method [8].

\section{Acquisition Method of Characteristic Signal}

Nonautonomous Chua's circuit (Figure 2) which we proposed in this study is a characteristic signal acquisition platform, which connects to the utility power with PV power system to obtain the voltage waveforms $V_{A}$ and $V_{B}$. The waveforms are used as the inputs to chaotic signal synchronization and extension detection method to determine whether the islanding effect occurs to instantly initiate the protection relays. 


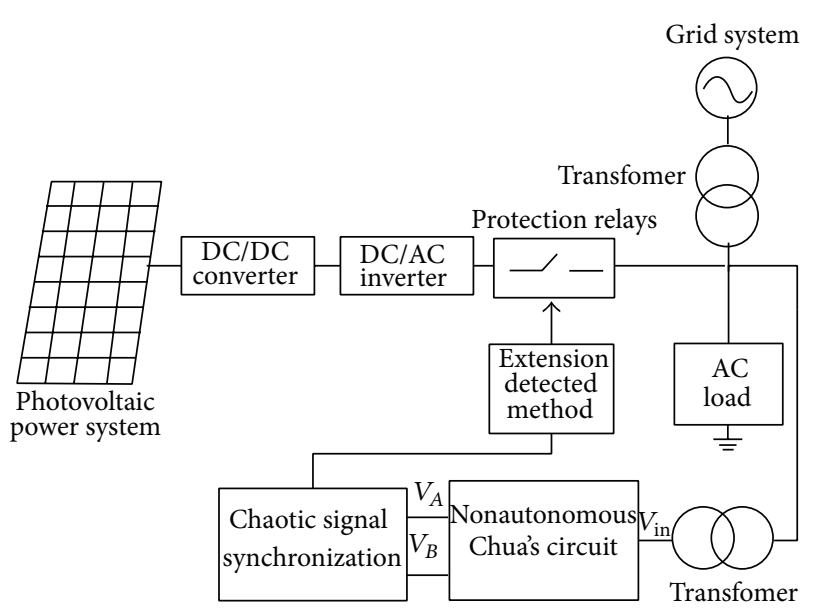

FIGURE 2: The proposed method for detecting islanding effect.

Given the abovedescribed background, this study, utilizing the dynamic trajectories of a chaotic system to convert the disturbance waveforms of power systems, extracts fewer characteristics and increases the detection accuracy based on the sensitive characteristics of chaos. Specifically, this study designs a chaotic synchronization detector to convert the input signal waveform and extracts prominent characteristics from the waveform. The extension theory in pattern recognition will be used to identify the type of the power disturbance signals. The overall scheme is shown in Figure 3.

3.1. Basic Introduction of Chua's Circuit. In this paper, Chua's circuit is a simple nonautonomous circuit designed and developed by Professor Chua in 1983 [12, 13] (Figure 4). It consists of three active components, capacitors, inductors, resistors, and a nonlinear resistor composition, $R L$ to Chua diode. According to Kirchhoff's circuit laws, Chua's circuit equations are as

$$
\begin{aligned}
& C_{1} \frac{d V_{c 1}}{d t}=-g V_{c 1}+i_{L 1}-i_{L 2}, \\
& C_{2} \frac{d V_{c 2}}{d t}=i_{L 1}-i_{R L}, \\
& L_{1} \frac{d i_{L 1}}{d t}=-V_{c 1}-i_{L 1} R_{1}+V_{i n} \sin (2 \pi k f t), \\
& L_{2} \frac{d i_{L 2}}{d t}=V_{c 1}-V_{c 2}-i_{L 2} R_{5},
\end{aligned}
$$

where $k$ is the number of higher harmonics. $i_{R L}$ is defined as

$$
i_{R L}=G_{a} V_{c 2}+\frac{1}{2}\left(G_{b}-G_{a}\right)\left[\left|V_{c 2}+E_{a}\right|-\left|V_{c 2}-E_{a}\right|\right],
$$

where $G_{a}$ and $G_{b}$ are the slopes and $E_{a}$ is breakpoint. Normal conditions voltage waveforms of nonautonomous Chua's circuit $V_{A}$ and $V_{B}$ are as shown in Figure 5.

3.2. Chaotic Synchronization. Pecora and Carroll showed that when the signs of the Lyapunov exponents for the subsystems are all negative, the chaotic system will synchronize and constructed a real set of chaotic synchronizing circuits [14]. In chaotic systems, the initial state has subtle change, which is gradually enlarged, and leads to significant difference eventually. Generally, the two synchronous chaotic systems are called master system and slave system. When the initial values of master and slave systems are different, the operation trajectories of the two chaotic systems are different. The basic formula for the chaotic synchronization is shown as in

$$
\lim _{t \rightarrow \infty}\left\|Y_{\text {slave }, i(t)}-X_{\text {master }, i(t)}\right\|, \quad i=1,2, \ldots, n,
$$

where $Y_{\text {slave }}$ is slave system and $X_{\text {master }}$ is main system.

This paper uses chaotic synchronization to analyze characteristics signal of system [15]. Master and slave chaotic system are as in the following equations.

Master:

$$
\begin{gathered}
\dot{x}_{1}=f_{1}\left(x_{1}, x_{2}, \ldots, x_{n}\right) \\
\dot{x}_{2}=f_{2}\left(x_{1}, x_{2}, \ldots, x_{n}\right) \\
\vdots \\
\dot{x}_{n}=f_{n}\left(x_{1}, x_{2}, \ldots, x_{n}\right) .
\end{gathered}
$$

Slave:

$$
\begin{gathered}
\dot{y}_{1}=f_{1}\left(y_{1}, y_{2}, \ldots, y_{n}\right) \\
\dot{y}_{2}=f_{2}\left(y_{1}, y_{2}, \ldots, y_{n}\right) \\
\vdots \\
\dot{y}_{n}=f_{n}\left(y_{1}, y_{2}, \ldots, y_{n}\right),
\end{gathered}
$$

where $f_{i}(i=1,2, \ldots, n)$ are non-linear functions. Equation (6), dynamic error equation, are formed from (4) and (5) by subtracting the error status.

$$
\begin{aligned}
& e_{1}=y_{1}-x_{1} \\
& e_{2}=y_{2}-x_{2} \\
& \quad \vdots \\
& e_{n}=y_{n}-x_{n}, \\
& \dot{e}_{1}=f_{1}\left(x_{1}, x_{2}, \ldots, x_{n}\right)-f_{1}\left(y_{1}, y_{2}, \ldots, y_{n}\right)=H_{1} \\
& \dot{e}_{2}=f_{2}\left(x_{1}, x_{2}, \ldots, x_{n}\right)-f_{2}\left(y_{1}, y_{2}, \ldots, y_{n}\right)=H_{2} \\
& \quad \vdots \\
& \dot{e}_{n}=f_{n}\left(x_{1}, x_{2}, \ldots, x_{n}\right)-f_{n}\left(y_{1}, y_{2}, \ldots, y_{n}\right)=H_{n},
\end{aligned}
$$

where $H_{i}(i=1,2, \ldots, n)$ are nonlinear equations and the dynamic error equation is a chaotic system. This paper uses the chaotic dynamic trajectory to mimic various system operating states, including periodic, nonperiodic, and random 


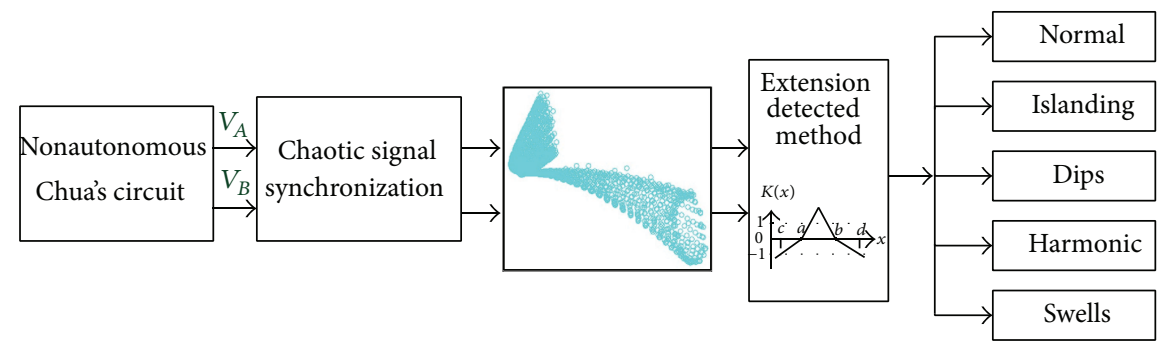

FIgURE 3: The proposed islanding detection system.

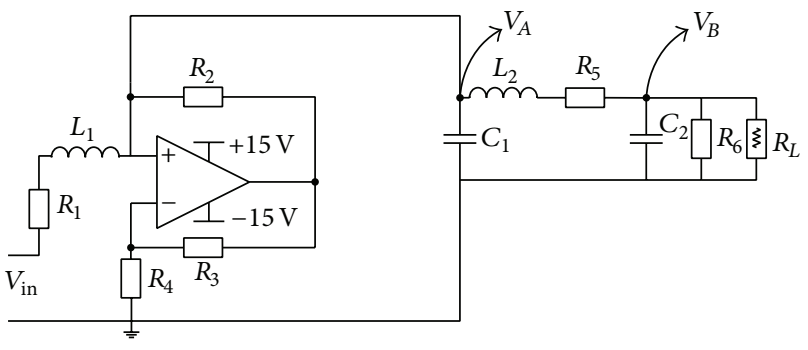

Figure 4: Chua's circuit diagram.

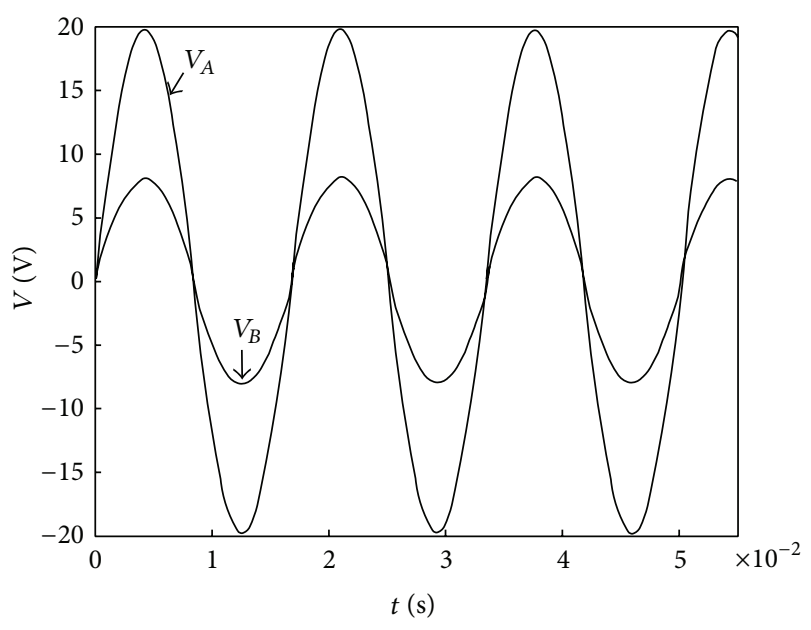

FIGURE 5: Output voltage waveforms in Chua's circuit.

states in the time domain, so as to identify the disturbance state of PV power systems. As a test framework, this study uses two Lorenz chaotic systems; one is the master system and the other is the slave system, expressed as in (7) and (8). The dynamic error state equation is worked out and expressed in matrix form as in (9).

Master:

$$
\begin{aligned}
& \dot{x}_{1}=\alpha\left(x_{2}-x_{1}\right) \\
& \dot{x}_{2}=\beta x_{1}-x_{1} x_{3}-x_{2} \\
& \dot{x}_{3}=x_{1} x_{2}-\gamma x_{3} .
\end{aligned}
$$

Slave:

$$
\begin{gathered}
\dot{y}_{1}=\alpha\left(y_{2}-y_{1}\right) \\
\dot{y}_{2}=\beta y_{1}-y_{1} y_{3}-y_{2} \\
\dot{y}_{3}=y_{1} y_{2}-\gamma y_{3} \\
{\left[\begin{array}{c}
\dot{e}_{1} \\
\dot{e}_{2} \\
\dot{e}_{3}
\end{array}\right]=\left[\begin{array}{ccc}
-\alpha & \alpha & 0 \\
\beta & -1 & 0 \\
0 & 0 & -\gamma
\end{array}\right]\left[\begin{array}{l}
e_{1} \\
e_{2} \\
e_{3}
\end{array}\right]+\left[\begin{array}{c}
y_{2} y_{3}-x_{2} x_{3} \\
-y_{1} y_{3}+x_{1} x_{3} \\
y_{1} y_{2}-x_{1} x_{2}
\end{array}\right],}
\end{gathered}
$$

where $e_{1}, e_{2}$, and $e_{3}$ are the chaotic dynamic error values of the main system and slave system; $\alpha, \beta$, and $\gamma$ are adjustment parameters. This research simulates five waveforms of the PV power systems including normal, islanding, harmonics, voltage swells, and voltage dips. This paper use two error values $e_{1}$ and $e_{2}$ to generate chaos error scatter patterns for islanding analysis.

\section{The Proposed Extension Detection Method}

PSIM and Matlab simulate nonautonomous Chua's circuit and power grid in this study. In order to detect slight changes in the PV power system, this study imported the original data into the chaotic synchronization-based detector module to form the chaos error scatter pattern. However, there were many error distribution points in the diagram; the centroid pattern was used as the characteristic of islanding detection to set the feature range and effectively reduce the quantity of the extracted features. Figure 6 shows the typical chaos error scatter patterns under normal condition, where the triangle is the center of chaos scatter patterns, and the four center characteristics (eight values from $V_{1}$ to $V_{8}$ ) are used as the input patterns of the proposed extension detection method.

In order to precisely distinguish genuine islanding effect from the power system quality issues, five PV power systems including normal, islanding, harmonics, voltage swells, and voltage dips are simulated in this study. The specific characteristics are (1) normal; (2) islanding is when the grid system and the photovoltaic system cut off; (3) harmonics is the power system have contain high frequency; (4) voltage swells occur between reference voltage 1.1 p.u and 1.8 p.u; (5) voltage dips occur between reference voltage 0.1 p.u and 0.9 p.u.

The proposed extension detection method is based on the extension theory. The extension set extends the fuzzy set from $[0,1]$ to $(-\infty, \infty)$. So it allows the researcher to define 

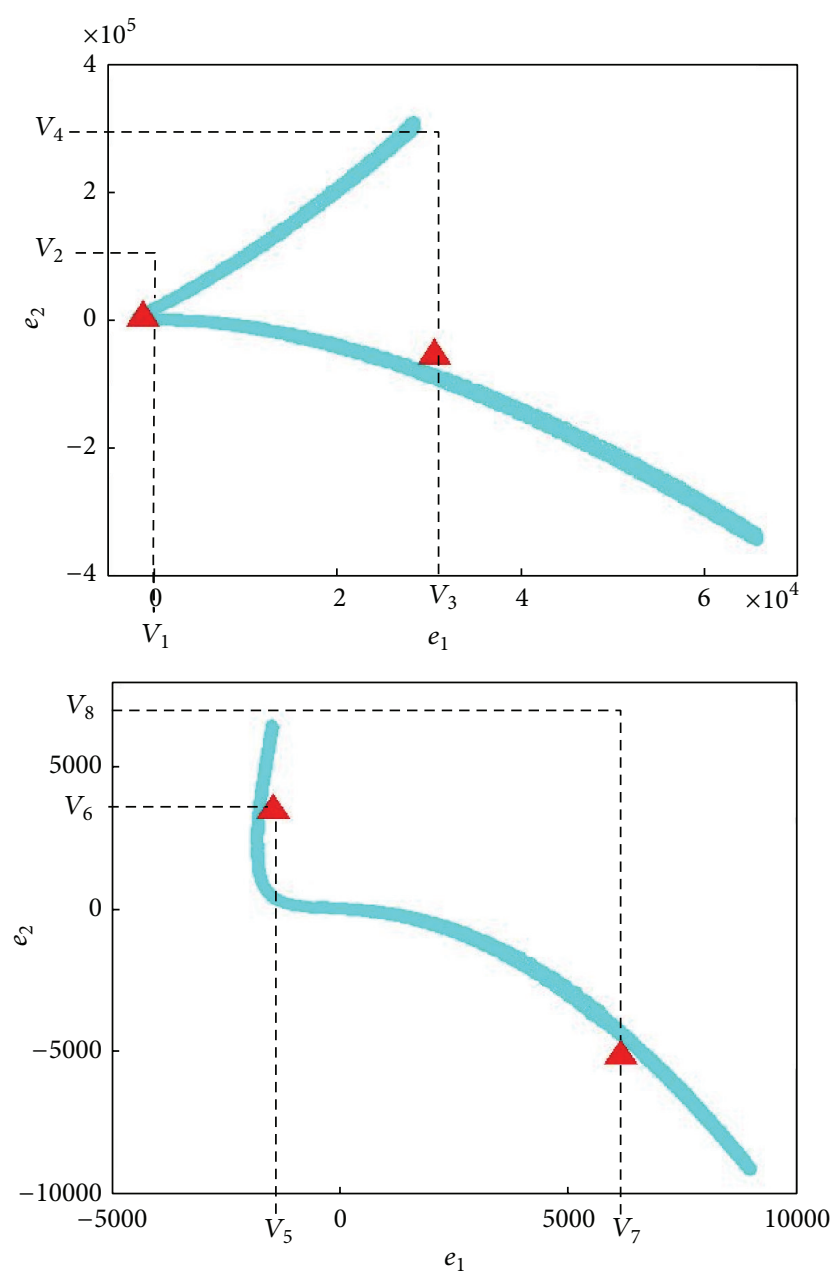

Figure 6: Typical chaos error scatter patterns.

a set that includes any data in the domain. According to the extension theory, $R=(N, C, V)$ is a multidimensional matter-element, $C=\left[c_{1}, c_{2}, \ldots, c_{n}\right]$ is a characteristic vector, and $V=\left[v_{1}, v_{2}, \ldots, v_{n}\right]$ is a value vector of $C$; then a multidimensional matter-element is defined as

$$
R=\left[\begin{array}{c}
N, c_{1}, v_{1} \\
c_{2}, v_{2} \\
\vdots \\
c_{n}, v_{n}
\end{array}\right]=\left[\begin{array}{c}
R_{1} \\
R_{2} \\
\vdots \\
R_{n}
\end{array}\right],
$$

where $R_{i}=\left(N, c_{1}, v_{1}\right)(i=1,2, \ldots, n)$ is defined as the submatter-element of $R$ and can be simplified as follows:

$$
R=(N, C, V) \text {. }
$$

According to extension theory $[16,17]$ and the testing results of this study, the upper and lower limits for each classical domain are set by the center of the chaos error scatter patterns, and the maximum and minimum values of the classical domain are shown in Table 1. The various numeric values about $c_{i}$ change at the condition of different power
TABLE 1: The matter element models of different categories.

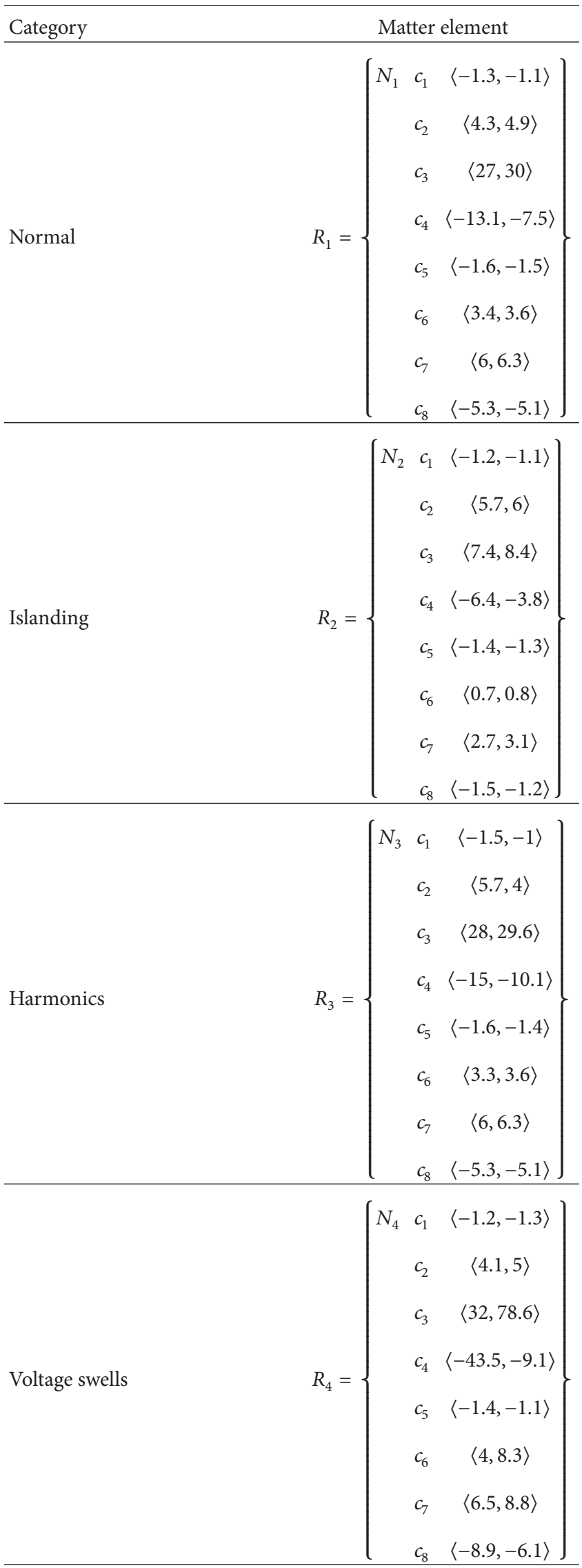


TABLE 1: Continued.

\begin{tabular}{llc}
\hline Category & Matter element \\
\hline Voltage dips & $R_{5}=\left\{\begin{array}{ccc}N_{5} & c_{1} & \langle-1.2,-0.9\rangle \\
& c_{2} & \langle 0.1,4.8\rangle \\
& c_{3} & \langle 1.3,23.6\rangle \\
& c_{4} & \langle-11.6,-0.3\rangle \\
& c_{5} & \langle-1.5,-0.4\rangle \\
& c_{6} & \langle 0.04,3.9\rangle \\
& c_{7} & \langle 0.5,6.5\rangle \\
& c_{8} & \langle-5.8,-0.07\rangle\end{array}\right\}$ \\
\hline
\end{tabular}

system. The methodology of deciding the values of $c_{i}$ is based on the simulation results. The best values of $c_{i}$ will be selected and therefore implementing those values to chips. The neighborhood domain is set by all classical domain maximum and minimum values, the values of neighborhood domain are set as

$$
R_{p}=\left\{\begin{array}{ccc}
N_{p} & c_{1} & \langle-1.6,-0.8\rangle \\
& c_{2} & \langle 0.1,8\rangle \\
c_{3} & \langle 1.2,80\rangle \\
c_{4} & \langle-50,-0.4\rangle \\
c_{5} & \langle-1.6,-1.5\rangle \\
c_{6} & \langle 0,85\rangle \\
c_{7} & \langle 0.4,9\rangle \\
c_{8} & \langle-9.8,0\rangle
\end{array}\right\},
$$

where $c_{1}$ to $c_{8}$ are eight input characteristics. After the element-matter model of islanding detection is formulated, the system detection of PV power systems can be initiated. The proposed extension detection algorithm is as follows [18].

Step 1. Establish the matter-element of each category such as

$$
R_{i}=\left[\begin{array}{ccc}
R_{i} & c_{1} & V_{i 1} \\
& c_{2} & V_{i 2} \\
& \vdots & \vdots \\
& c_{8} & V_{i 8}
\end{array}\right], \quad i=1,2, \ldots, 5
$$

where $V_{i j}=\left\langle a_{i j}, b_{i j}\right\rangle, j=1,2, \ldots, 8$ are the upper and lower characteristic values of classical domain in the $i$ th category, and the detail setting is shown in Table 1.
Step 2. Input a tested matter-element:

$$
R_{t}=\left(R_{t}, C, V_{t}\right)=\left[\begin{array}{ccc}
R_{t} & c_{1} & v_{t 1} \\
& c_{2} & v_{t 2} \\
& \vdots & \vdots \\
& c_{8} & v_{t 8}
\end{array}\right] \text {, }
$$

where $v_{t 1}$ to $v_{t 8}$ are characterized values of $c_{1}$ to $c_{8}$.

Step 3. Calculate the relation degree of the tested element with the category characteristic using

$$
K_{i j}\left(v_{t j}\right)= \begin{cases}\frac{-0.5 \rho\left(v_{t j}, V_{i j}\right)}{\left|V_{i j}\right|} & v_{t j} \in V_{i j} \\ \frac{\rho\left(v_{t j}, V_{i j}\right)}{\rho\left(v_{t j}, V_{p j}\right)-\rho\left(v_{t j}, V_{i j}\right)} & v_{t j} \notin V_{i j}, \\ i=1,2, \ldots, 5 ; \quad j=1,2, \ldots, 8,\end{cases}
$$

where

$$
\begin{aligned}
& \rho\left(v_{t j}, V_{i j}\right)=\left|v_{t j}-\frac{a_{i j}+b_{i j}}{2}\right|-\frac{b_{i j}-a_{i j}}{2}, \\
& \rho\left(v_{t j}, V_{p j}\right)=\left|v_{t j}-\frac{a_{p j}+b_{p j}}{2}\right|-\frac{b_{p j}-a_{p j}}{2} .
\end{aligned}
$$

$a_{i j}$ : $j$ th lower characteristic values of classical domain in the $i$ th category. $b_{i j}$ : $j$ th upper characteristic values of classical domain in the $i$ th category. $V_{p j}$ : jth characteristic values of neighborhood domain, or $V_{p j}=\left\langle a_{p j}, b_{p j}\right\rangle \cdot a_{p j}$ : jth lower characteristic values of neighborhood domain. $b_{p j}: j$ th upper characteristic values of neighborhood domain.

Step 4. Set the weights of the characteristics $W_{1}, W_{2}, \ldots, W_{8}$, according to the importance of every characteristic in the detection process. In order to reach high detection accuracy, the weights of design order from $c_{1}$ to $c_{8}$ are $0.1,0.2,0.2,0.1$, $0.1,0.1,0.1$, and 0.1 in this study.

Step 5. Calculate the relation coefficients for each category $\lambda_{i}$ as

$$
\lambda_{i}=\sum_{j=1}^{8} W_{j} K_{i j}, \quad i=1,2, \ldots, 5 .
$$

Step 6. Normalize the values of the relation coefficients into an interval between 1 and -1 as

$$
\lambda_{i}^{\prime}=\frac{2 \lambda_{i}-\lambda_{\min }-\lambda_{\max }}{\lambda_{\max }-\lambda_{\min }}, \quad i=1,2, \ldots, 5 .
$$

Step 7. Ranking the normalized relation coefficients to detect the category of test element, the detection rule is as

$$
\text { IF }\left(\lambda_{k}^{\prime}=1\right) \text { than the type of } R_{t} \text { is } N_{k} \text {. }
$$



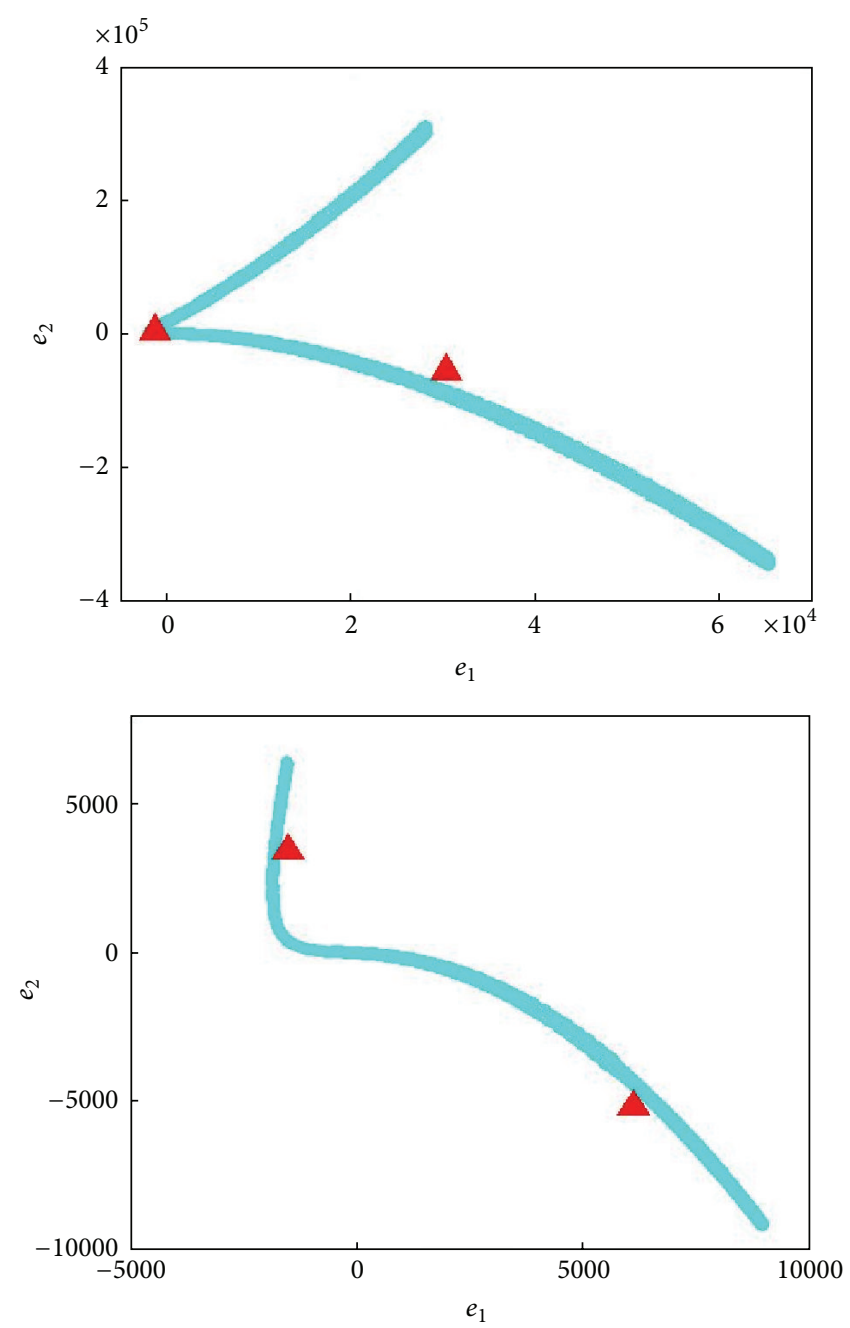

FIGURE 7: Chaos error scatter patterns under normal condition.

The major category is $N_{k}$ as shown in Table 1 , when $\lambda_{k}^{\prime}=1$ and is impossible to classify to $N_{k}$ when $\lambda_{k}^{\prime}=-1$. Other categories can be justified depending on the values of the relation coefficients. Larger relation coefficients demonstrate higher possibility to this category, otherwise lower.

Step 8. Go back to Step 2 for the next test data until all the whole sets have been done.

\section{Simulation Results}

To demonstrate the effectiveness of the proposed method, 500 sets of tested data are simulated using PSIM software. This paper uses a 66-PV (w) panel to simulate the distributed power source and parallel connection to $110 \mathrm{~V} 60 \mathrm{~Hz}$ main supply. The specifications of the PV panels for open-circuit voltage and short-circuit current are $21.7 \mathrm{~V}$ and $3.45 \mathrm{~A}$, respectively. The ideal electric power supply only contains the fundamental frequency component. But when it is delivered to the client-side, the voltage waveform possesses harmonic components due to long-distance delivery, nonlinear loads,
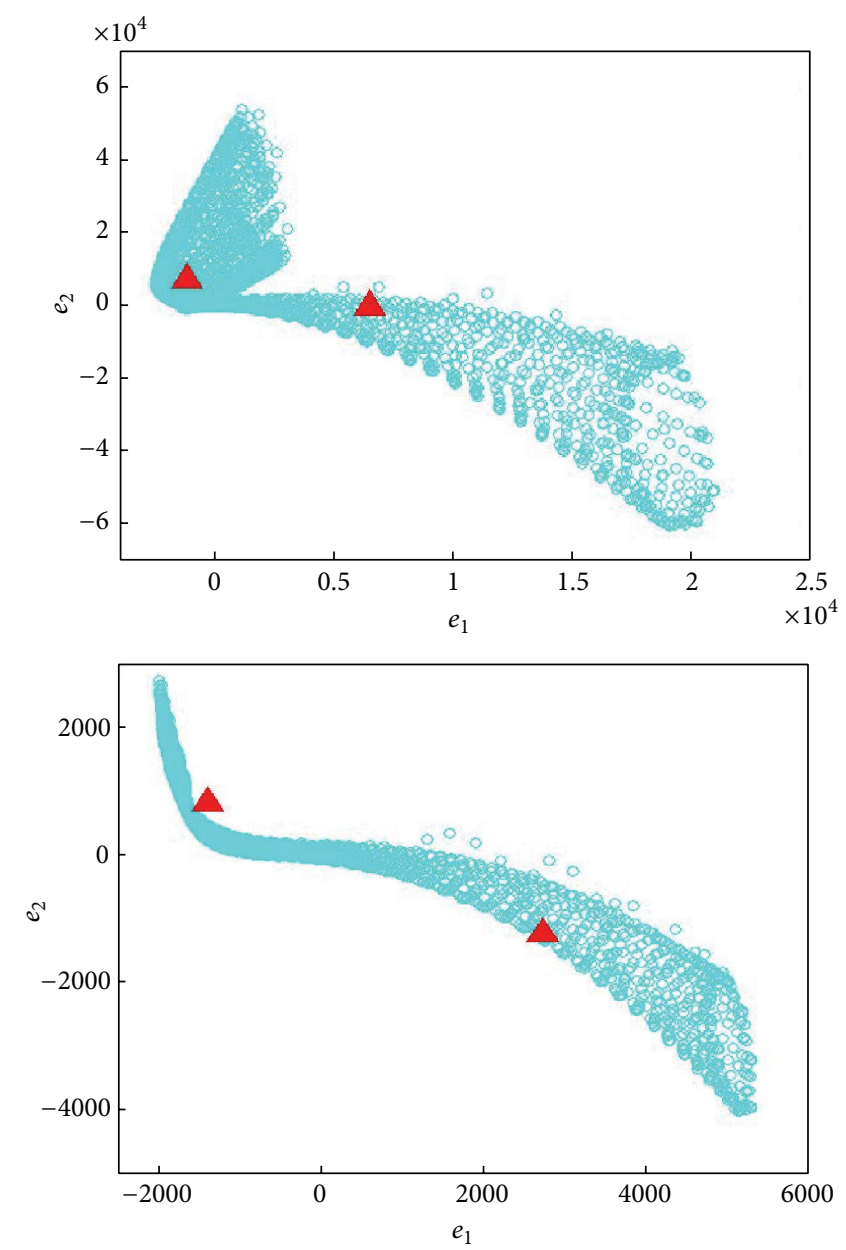

FIGURE 8: Chaos error scatter patterns under islanding condition.

nonlinear electricity, or electronic equipment. We set $1 \% \sim 10 \%$ harmonic components in the study. Voltage swells are the root-mean-square value of the voltage and are within the range of 1.1-1.8 p.u., and continuing 0.5 30 cycles; voltage dips are the root-mean-square value of the fundamental frequency voltage and are within the range of 0.1-0.9 p.u. and continuing $0.5 \sim 30$ cycles. When the voltage is lower than 0.1 , it is referred to power interruption, and the PV system will produce the islanding condition. Figures 7 to 11 show the chaotic scatter patterns under different test conditions. The conditions include normal, islanding effect, harmonic, voltage swells, and voltage dips.

According to the centroid of chaos scatter diagram in Figure 7, the islanding effect can be easily detected, which is significantly different from other conditions. So the protection relay can function in time to cut off the main supply to eliminate the casualties of maintenance personnel or cause the heavy damage on power users, power supply system, or electrical equipment. Moreover, the harmonic condition is close to normal condition in a few cases, so the system may misrecognize its state. However, when the islanding effect occurs, the waveform and centroid are apparently 

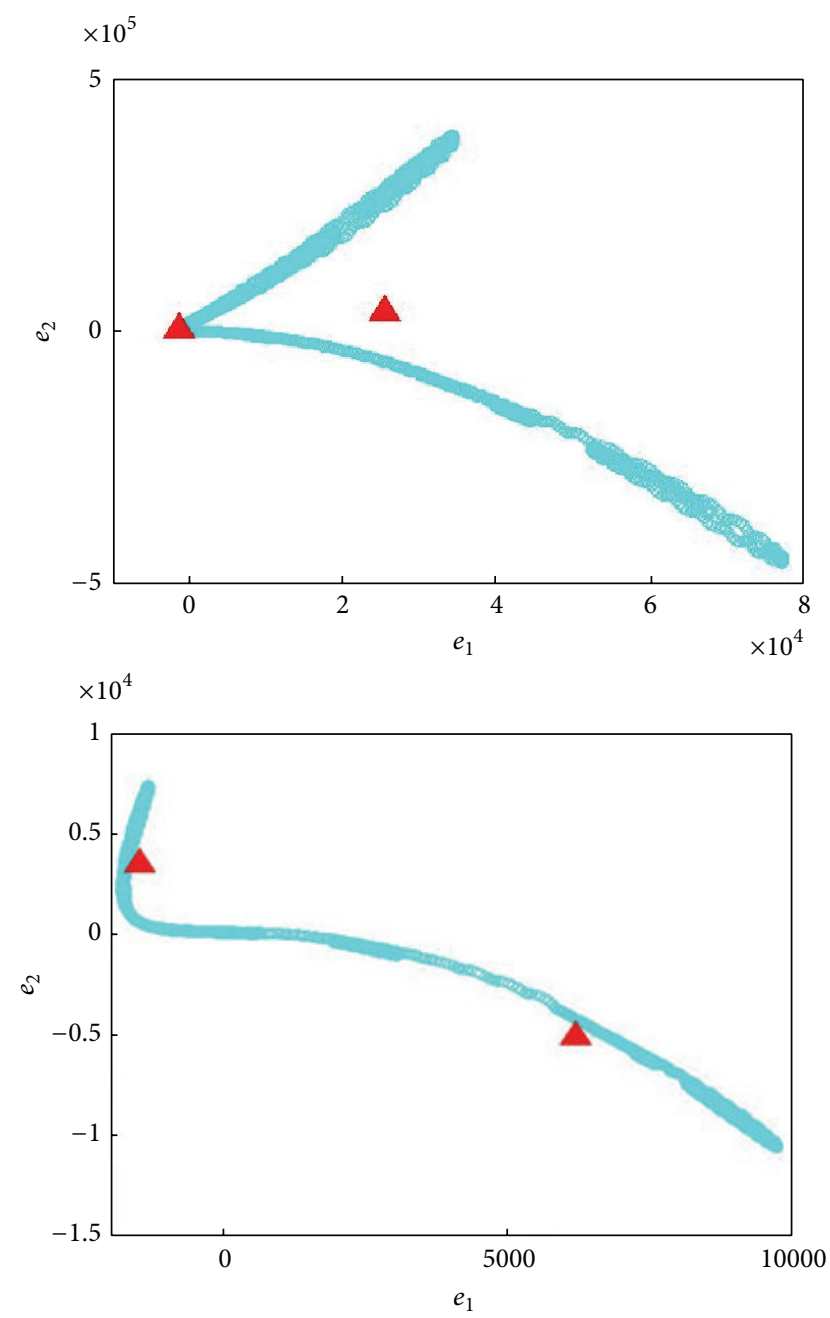

FIGURE 9: Chaos error scatter patterns under harmonics condition.

different from normal and other power quality issues. Therefore, the islanding operation can be identified accurately and the system can be immediately shut off.

Table 2 shows the typical patterns of the proposed method; 10 sample data are selected from 500 test data randomly, in which sample data number 8 is harmonic state and sample data number 9 is normal state. The values are very close to each other according to the centroid characteristics, but both are significantly different from islanding state. Thus, the power quality problem can be eliminated, and the protection relay correctly functions.

Using the proposed method, the partial detection results are shown in Table 3 , and the classification results for all 500 data sets are shown in Table 4. While the relation degree with the islanding condition equals 1 (the maximum value), sample number 1 is classified as in islanding state. Moreover, samples number 9 is classified as in normal state as the relation degree with the normal condition equaling 1 . Although the detection result is normal, it can also provide useful
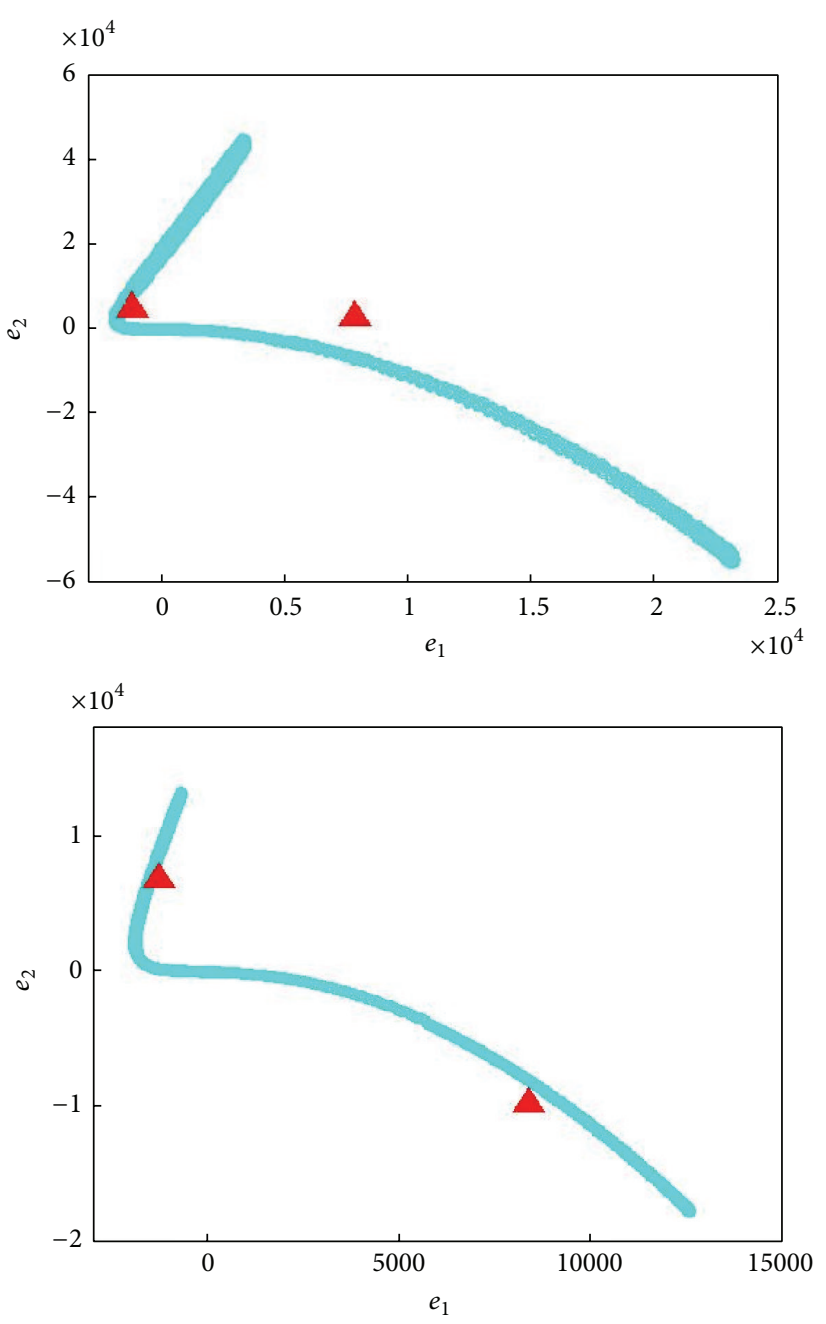

FIGURE 10: Chaos error scatter plot under voltage swells.

information for future analysis when the harmonic correlation grade ranks the second. On the contrary, the sample island correlation grade is -1 , meaning that it is unlikely to be islanding effect. Therefore, the proposed detection method can efficiently and effectively distinguish islanding effect from the power quality problem.

Various detection methods are also used to test the same PV power system. The testing time and accuracy are shown in Table 5. The detection times of phase jump and voltage harmonic methods are relatively proposed method long. The phase jump detection method has high accuracy for nonresistive loads, but it fails when the load is resistive [19]. The voltage harmonic detection method is unable to resist the interference of power quality, and misrecognition occurs. The power changing method is faster and more accurate than voltage harmonic method. However, when the output power of PV power system approaches the load consumed power, this method cannot detect islanding effect. Among them all, our proposed method has the shortest detection time and can precisely identify the islanding effect. 
TABLE 2: Typical patterns of proposed method (partial results).

\begin{tabular}{lcccccccccc}
\hline Sample & $v_{1}$ & $v_{2}$ & $v_{3}$ & $v_{4}$ & $v_{5}$ & $v_{6}$ & $v_{7}$ & $v_{8}$ & Actual category \\
\hline 1 & -1.19 & 5.78 & 7.83 & -4.78 & -1.38 & 0.79 & 2.85 & -1.29 & Islanding \\
2 & -1.18 & 5.85 & 8.23 & -5.82 & -1.38 & 0.79 & 2.98 & -1.38 & Islanding \\
3 & -1.19 & 5.78 & 8 & -5.15 & -1.40 & 0.79 & 2.91 & -1.32 & Islanding \\
4 & -0.95 & 0.16 & 1.39 & -0.43 & -0.43 & 0.04 & 0.49 & -0.08 & Dips \\
5 & -1.2 & 4.35 & 48.26 & -18.81 & -1.16 & 7.37 & 8.98 & -10.42 & Swells \\
6 & -1.43 & 5.08 & 28.59 & -11.59 & -1.54 & 3.45 & 6.27 & -5.31 & Harmonic \\
7 & -1.36 & 5.81 & 28.51 & -13.79 & -1.55 & 3.46 & 6.12 & -5.14 & Harmonic \\
8 & -1.43 & 5.08 & 28.64 & -11.61 & -1.54 & 3.45 & 6.29 & -5.32 & Harmonic \\
9 & -1.21 & 4.48 & 27.80 & -11 & -1.51 & 3.48 & 6.22 & -5.27 & Normal \\
10 & -1.21 & 4.49 & 27.83 & -11.35 & -1.50 & 3.52 & 6.13 & -5.18 & Normal \\
\hline
\end{tabular}

TABLE 3: Testing results of the proposed extension detection method (partial results).

\begin{tabular}{|c|c|c|c|c|c|c|c|}
\hline Samples & $\begin{array}{c}\text { Normal } \\
\text { correlation }\end{array}$ & $\begin{array}{l}\text { Islanding } \\
\text { correlation }\end{array}$ & $\begin{array}{l}\text { Harmonic } \\
\text { correlation }\end{array}$ & $\begin{array}{c}\text { Swells } \\
\text { correlation }\end{array}$ & $\begin{array}{c}\text { Dips } \\
\text { correlation }\end{array}$ & $\begin{array}{c}\text { Actual } \\
\text { category }\end{array}$ & $\begin{array}{c}\text { Detection } \\
\text { category }\end{array}$ \\
\hline 1 & -1 & 1 & -0.45 & -0.90 & 0.49 & Islanding & Islanding \\
\hline 2 & -1 & 1 & -0.39 & -0.90 & 0.54 & Islanding & Islanding \\
\hline 3 & -1 & 1 & -0.40 & -0.92 & 0.58 & Islanding & Islanding \\
\hline 4 & -1 & -0.98 & -0.97 & -1 & 1 & Dips & Dips \\
\hline 5 & -0.92 & -0.83 & -0.97 & 1 & -1 & Swells & Swells \\
\hline 6 & 0.16 & -1 & 1 & -0.41 & -0.12 & Harmonic & Harmonic \\
\hline 7 & 0.33 & -1 & 1 & -0.12 & 0.20 & Harmonic & Harmonic \\
\hline 8 & 0.31 & -1 & 1 & -0.07 & 0.17 & Harmonic & Harmonic \\
\hline 9 & 1 & -1 & 0.57 & 0.31 & 0.35 & Normal & Normal \\
\hline 10 & 1 & -1 & 0.65 & 0.36 & 0.38 & Normal & Normal \\
\hline
\end{tabular}

TABle 4: Classification table.

\begin{tabular}{|c|c|c|c|c|c|c|}
\hline \multirow{2}{*}{ Actual group } & \multicolumn{6}{|c|}{ Predicted group } \\
\hline & Normal & Islanding & Harmonics & Voltage swells & Voltage dips & Total \\
\hline Normal & 98 & 0 & 2 & 0 & 0 & 100 \\
\hline Islanding & 0 & 100 & 0 & 0 & 0 & 100 \\
\hline Harmonics & 8 & 0 & 92 & 0 & 0 & 100 \\
\hline Voltage swells & 0 & 0 & 0 & 100 & 0 & 100 \\
\hline Voltage dips & 0 & 0 & 0 & 0 & 100 & 100 \\
\hline Total & 106 & 100 & 94 & 100 & 100 & 500 \\
\hline
\end{tabular}

TABLE 5: Detection performances of different methods.

\begin{tabular}{lcc}
\hline Detection methods & $\begin{array}{c}\text { Detection times, } \\
\text { ms }\end{array}$ & Accuracy \\
\hline Phase jump method & 17 & $95 \%$ \\
Voltage harmonic method & 17 & $85 \%$ \\
Power changing method & 14 & $90 \%$ \\
Proposed method & 12 & $98 \%$ \\
\hline
\end{tabular}

\section{Simulation Results}

The islanding effect is an inevitable problem in distributed power source, and it causes the damage on maintainers or electrical equipment. Therefore, this paper proposes a novel detection method using the chaotic signal synchronization with extension theory to analyze the islanding effect of the $\mathrm{PV}$ power system. The simulation conditions include normal, islanding, harmonic, voltage swell, and voltage dip. Test results show that the proposed method can not only detect the main states of $\mathrm{PV}$ power systems, but also provide useful information for future analysis by the relative relation degrees. Based on the results, the following conclusions are proposed.

(1) Proposed method combining Chua's circuit and chaotic signal synchronization is effective on islanding detection, and the architecture is easy to be implemented in hardware circuit. 

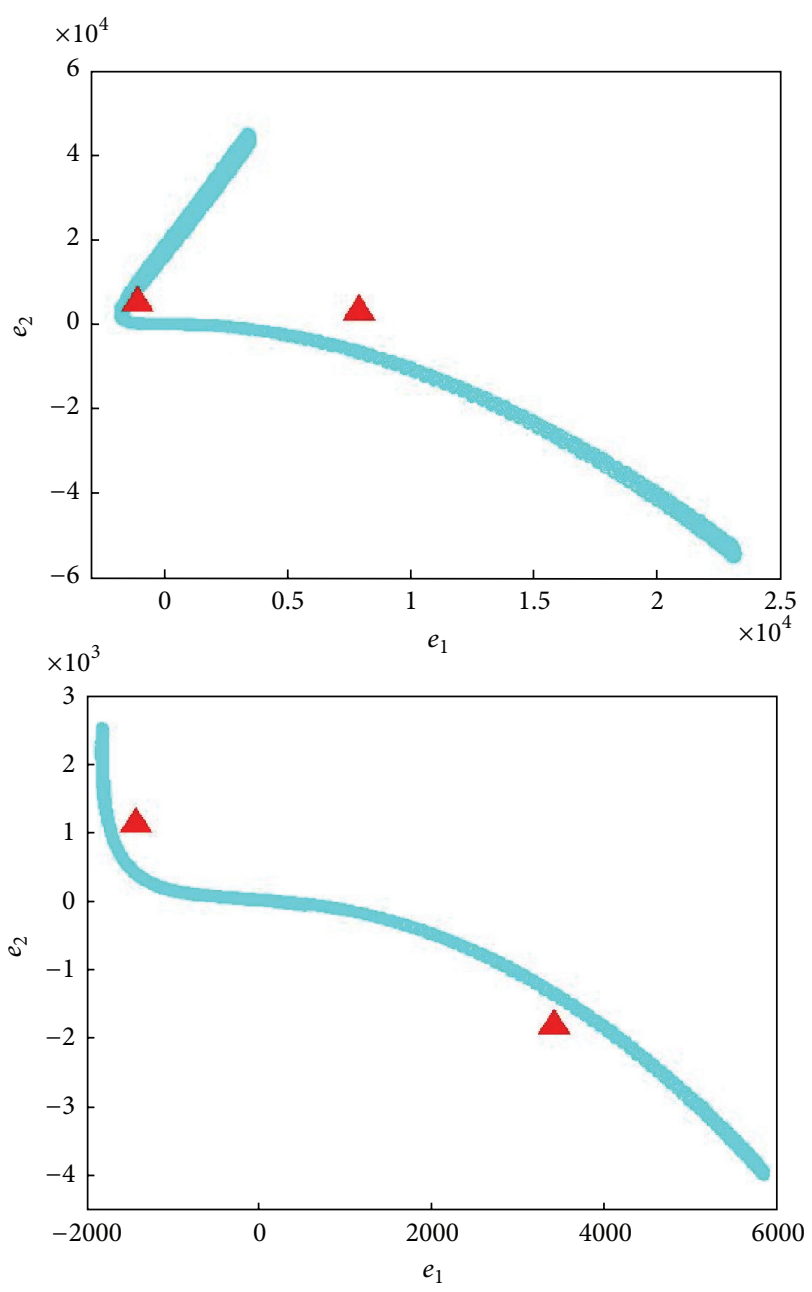

FIGURE 11: Chaos error scatter patterns under voltage dips.

(2) The algorithm combining chaotic signal synchronization with extension detection is easy to be implemented by chip for DC/AC inverter, and it effectively increases the accuracy of detecting islanding effect.

(3) Experimental results show that our proposed method significantly achieves high degree of detection accuracy.

\section{Conflict of Interests}

The authors declare that there is no conflict of interests regarding the publication of this paper.

\section{References}

[1] Y. K. Wu and H. J. Lin, "A research review of small wind turbines in urban areas," Monthly Journal of Taipower's Engineering, vol. 773, pp. 59-73, 2014.

[2] C.-D. Yue, C.-M. Liu, and E. M. L. Liou, "A transition toward a sustainable energy future: feasibility assessment and development strategies of wind power in Taiwan," Energy Policy, vol. 29, no. 12, pp. 951-963, 2001.
[3] J. S. You, Y. T. Cheng, and M. T. Tseng, "Design and installation of a thin-film $10 \mathrm{kWp}$ demonstration PV system at Taipower headquarters," Monthly Journal of Taipower's Engineering, vol. 775, pp. 69-84, 2013.

[4] L. A. C. Lopes and H. Sun, "Performance assessment of active frequency drifting islanding detection methods," IEEE Transactions on Energy Conversion, vol. 21, no. 1, pp. 171-180, 2006.

[5] X. Ding, P. A. Crossley, and D. J. Morrow, "Islanding detection for distributed generation," Journal of Electrical Engineering \& Technology, vol. 2, no. 1, pp. 19-28, 2007.

[6] G.-K. Hung, C.-C. Chang, and C.-L. Chen, "Automatic phaseshift method for islanding detection of grid-connected photovoltaic inverters," IEEE Transactions on Energy Conversion, vol. 18, no. 1, pp. 169-173, 2003.

[7] F. de Mango, M. Liserre, A. Dell'Aquila, and A. Pigazo, "Overview of anti-islanding algorithms for PV systems. Part I: passive methods," in Proceedings of the 12th International Power Electronics and Motion Control Conference, pp. 1878-1883, September 2006.

[8] M. A. Redfern, O. Usta, and G. Fielding, "Protection against loss of utility grid supply for a dispersed storage and generation unit," IEEE Transactions on Power Delivery, vol. 8, no. 3, pp. 948954, 1993.

[9] A. G. Jha, A. P. Das, and A. Kumar, "Effects of electromagnetic interference on non-autonomous chaotic circuits," in Proceedings of the 4th International Conference on Computers and Devices for Communication, pp. 1-4, December 2009.

[10] Y. K. Wu, Y. Q. Huang, and W. G. Chang, "Establishment of control technologies and simulation platform under various operation modes of micro grids," Monthly Journal of Taipower's Engineering, vol. 776, pp. 54-69, 2013.

[11] M. Liserre, A. Pigazo, A. Dell'Aquila, and V. M. Moreno, "An anti-islanding method for single-phase inverters based on a grid voltage sensorless control," IEEE Transactions on Industrial Electronics, vol. 53, no. 5, pp. 1418-1426, 2006.

[12] S. R. Huang, Y. H. Ma, J. H. Chou et al., "Application Wigner ville distribution (WVD) algorithm analysis and identify the chaotic signals of non-autonomous Chua's circuit for islanding detection," in Proceedings of the 34th Symposium on Electrical Power Engineering, pp. 1691-1696, Taipei, Taiwan, December 2012.

[13] L. O. Chua and G. N. Lin, "Canonical realization of Chua's circuit family," IEEE Transactions on Circuits and Systems, vol. 37, no. 7, pp. 885-902, 1990.

[14] L. M. Pecora and T. L. Carroll, "Synchronization in chaotic systems," Physical Review Letters, vol. 64, no. 8, pp. 821-824, 1990.

[15] H. Huijberts, H. Nijmeijer, and R. Willems, "System identification in communication with chaotic systems," IEEE Transactions on Circuits and Systems I: Fundamental Theory and Applications, vol. 47, no. 6, pp. 800-808, 2000.

[16] M.-H. Wang, K.-H. Chao, G. J. Huang, and H.-H. Tsai, "Application of extension theory to fault diagnosis of automotive engine," ICIC Express Letters, vol. 5, pp. 1293-1299, 2011.

[17] M. H. Wang, "Application of extension theory to vibration fault diagnosis of generator sets," IEE Proceedings-Generation, Transmission and Distribution, vol. 151, no. 4, pp. 503-508, 2004.

[18] M. H. Wang and H. H. Tsai, "Fuel cell fault forecasting system using grey and extension theories," IET Renewable Power Generation, vol. 6, no. 6, pp. 373-380, 2012.

[19] C.-C. Hou and Y.-C. Chen, "Active anti-islanding detection based on pulse current injection for distributed generation systems," IET Power Electronics, vol. 6, no. 8, pp. 1658-1667, 2013. 

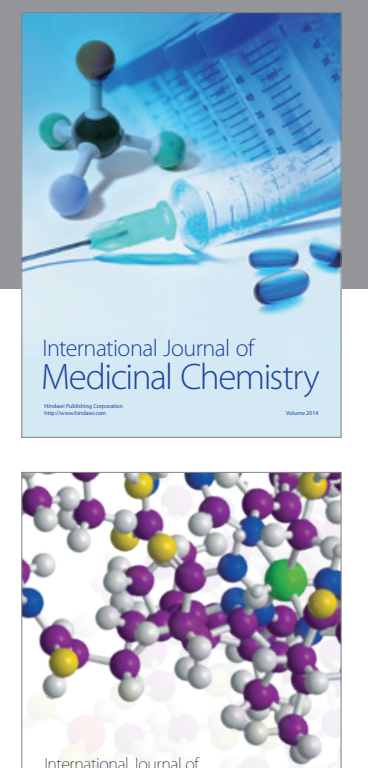

\section{Carbohydrate} Chemistry

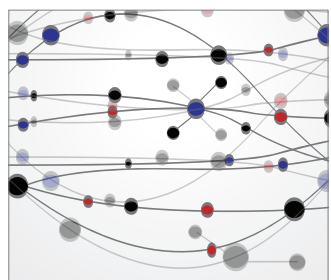

The Scientific World Journal
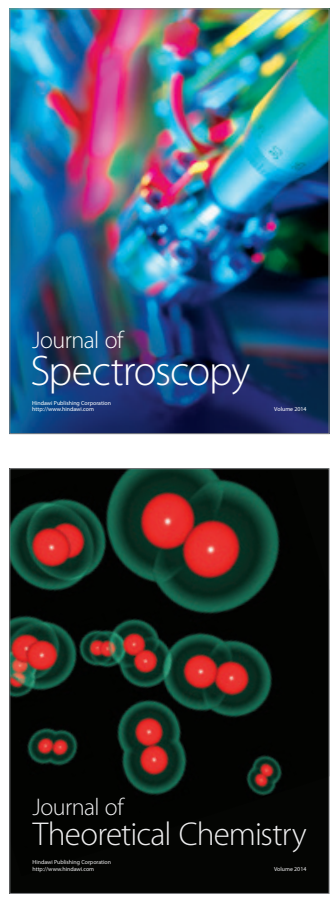
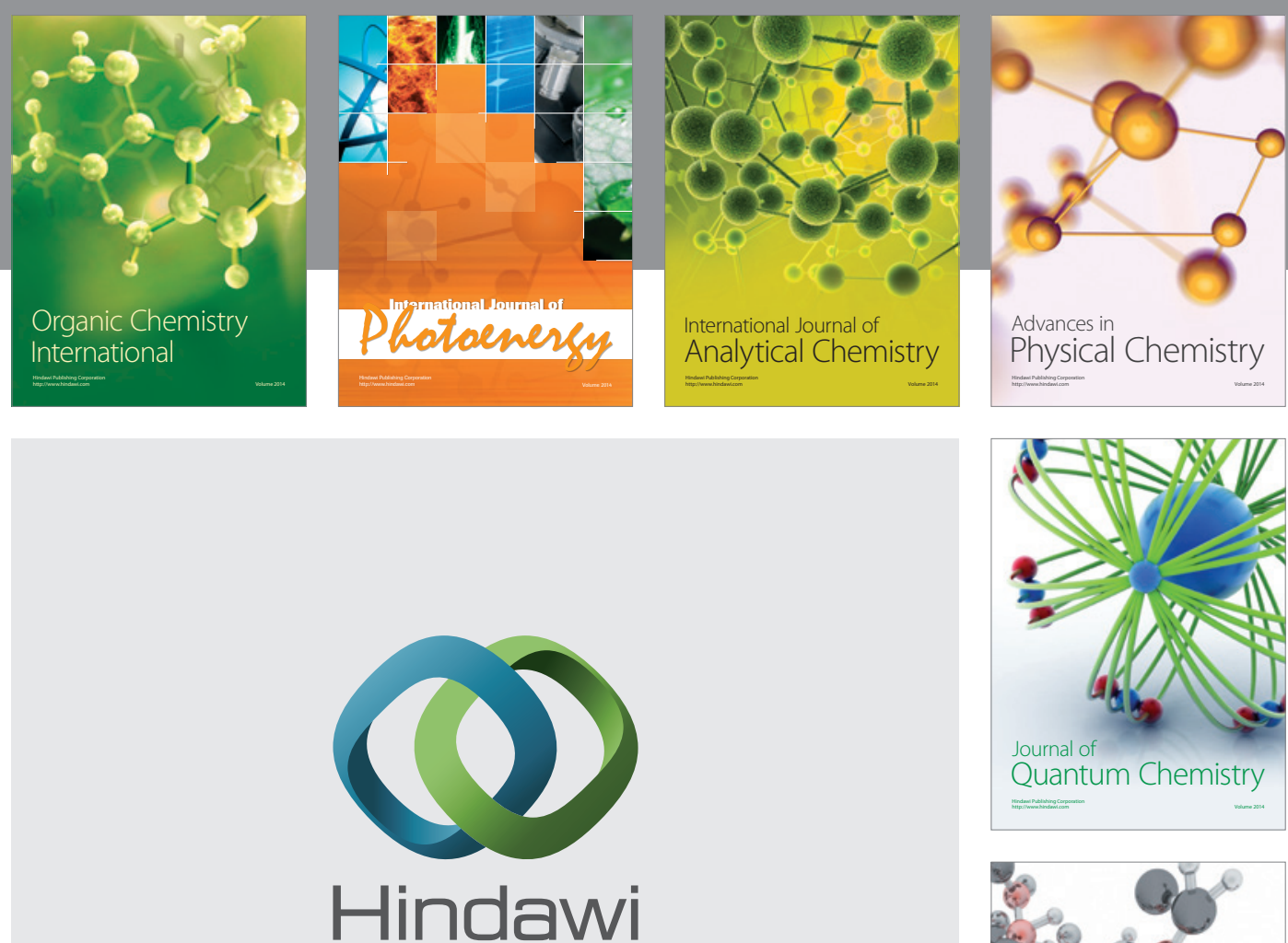

Submit your manuscripts at

http://www.hindawi.com

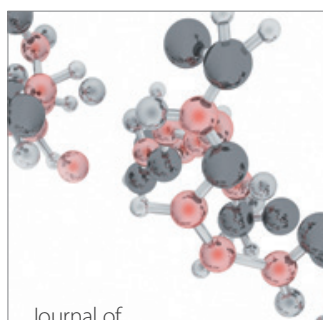

Analytical Methods

in Chemistry

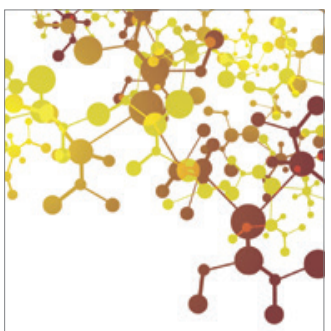

Journal of

Applied Chemistry

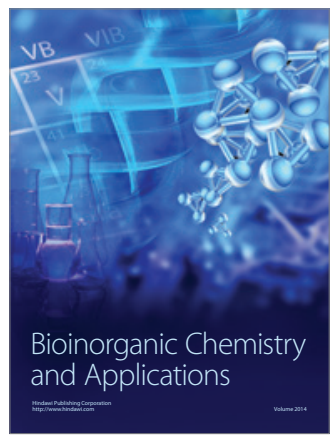

Inorganic Chemistry
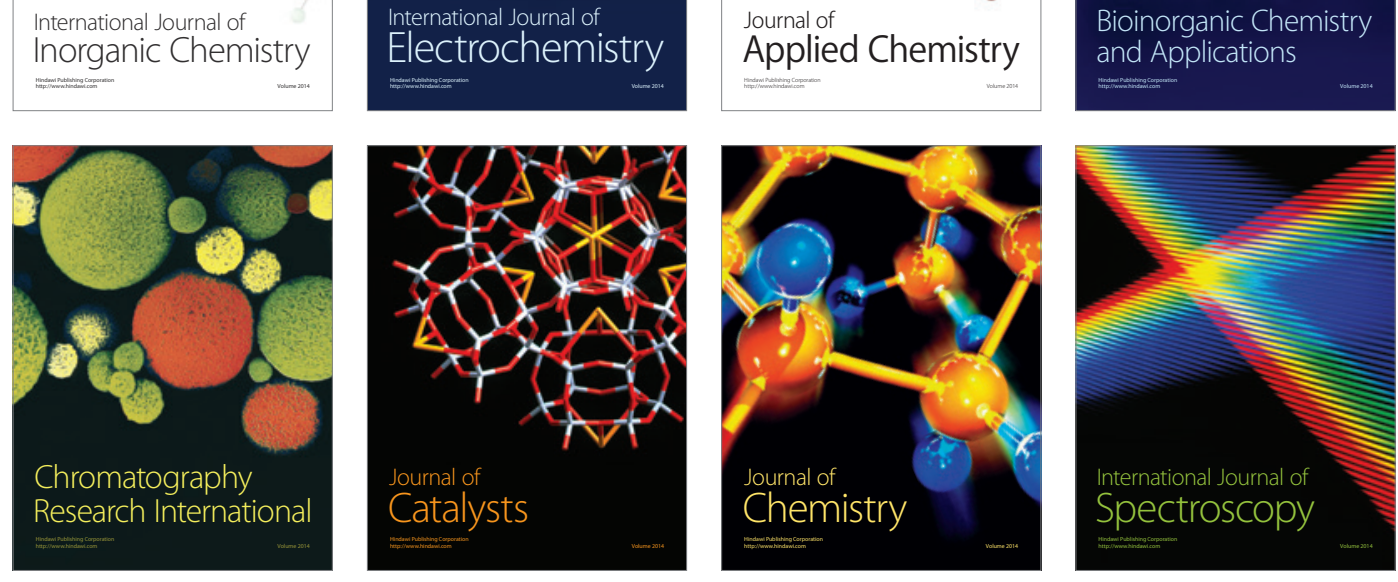